\title{
19. Yüzyılda Keçeci-zâde İzzet Mollâ'nın Muakkibi Olan Bir Şair: Hanyalı Şefîk Efendi ve Ona Tanıklık Eden Gazelleri
}

\author{
A Poet in The Nineteenth Century Who Was A Follower of Keçeci-Zâde Izzet Molla: \\ Hanyali Şefik Efendi And Gazels That Are an Example of Him
}

Esra KILIÇ

Özet

Nazirecilik geleneği Divan şiirinde önemli bir yere sahiptir. Bazı nazireler üstad şairlerin izinden gitmek amacıyla yazılmıştır. Bu tür nazirelerde iddiasız ve sayg1lı bir üslup göze çarpar. Bu makalede Divan şiirinin son yüzy1lında yaşamış bir şair olan Mehmet Şefik Efendi'nin divançesinden hareketle üstad kabul ettiği Keçeci-zâde İzzet Molla'dan tanzir ettiği şiirler şekil ve muhteva yönünden incelenecektir.

Anahtar Kelimeler: Nazire, Keçeci-zâde İzzet Molla, Hanyalı Şefik Efendi.

\begin{abstract}
The "nazirecilik" tradition has an important place in the Divan poetry. Some nazires were written with the objective of following in the footsteps of the master poets. An unpretentious and respectful style are conspicuous in these types of nazires. Whereas, in this article, it will be attempted to examine from the aspect of form and contents in accordance with the divançe by Mehmet Şefik Efendi, who was a poet who lived in the last century of the divan poetry and whose poems were resembling those by Keçeci-zâde İzzet Molla, who was accepted to be an expert.

Key Words: Nazire, Keçeci-zâde İzzet Molla, Hanyalı Şefik Efendi
\end{abstract}

Doktora Öğrencisi, Gazi Üniversitesi, Sosyal Bilimler Enstitüsü esra_k1905@hotmail.com 


\section{Giriş}

Nazire, edebiyat terimi olarak bir şairin manzum bir eserine, daha ziyade gazeline, başka bir şair tarafından aynı vezin ve kafiyede yazılan şiir demektir (İsen 2005:262). Nazire yazmak, nazireleşmek, bazı şairlerin şairliklerinin en büyük özelliği durumundadır. Bunların şiir faaliyetleri daha çok nazireye dayanır (Kurnaz 2007:41). Nazire yazmanın en bilinen şekli hemen hemen herkesçe tanınan, sanat değeri anlaşılmı̧ ve tartışmasız kabul edilmiş şairleri tanzir etmektir. Bu tür nazireler, tanzir edilen şiirin sahibine duyulan saygı, ilgi ve hayranlık dolayısıyla kaleme alınmıştır. Bunlarda bir üstünlük iddiası güdülmeden beğenilen sanatkârın verdiği ürünün bir benzeri ortaya konularak onunla hem-hâl olma arzusu söz konusudur. Böyle bir yaklaşımla yazılan nazirelerin en belirgin özelliği iddiasız olmaları ve saygılı bir üslûp taşımalarıdır (Köksal 2006:101).

Divan şiirinin son yüzyılında yaşamış bir şair olan Mehmet Şefik Efendi’nin Keçeci-zâde İzzet Molla'dan tanzir ettiği şiirlerin de bu tür nazire anlayışıyla yazıldığı tespit edilmiştir. Mehmet Şefîk Efendi’nin divançesi tarandığında Keçeci-zâde İzzet Molla’nın etkileri görülmüştür. Mehmet Şefîk Efendi 4 manzumesinde İzzet adlı bir şairin pey-revi olduğunu belirtir. Mehmet Şefîk Efendi’nin Mevlevî bir şair olması dolayısıyla bu şairin Keçeci-zâde İzzet Molla olabileceği düşünülmüştür. Divanları tarandığında ise manzumelerinde görülen benzerlikler nedeniyle bu şairin Keçeci-zâde İzzet Molla olduğu tespit edilmiştir.

\section{Mehmet Şefik Efendi'nin Hayatı}

19. yüzyılda yaşamış Mevlevî şairlerden biri olan Mehmet Şefik Efendi, Girit’in Hanya sancağında doğmuştur. Hanyalı İbrahim'in oğludur. Hayatı hakkında yeterli bilginin bulunmadı̆̆1 Mehmet Şefik Efendi, ömrünü Hanya'da geçirmiş ve 12 Eylül 1871/26 Cemaziye'l-âhir 1288 tarihinde Hanya'da vefat etmiştir. Ölümünden sonra cebinden çıkan manzume de kendi ölüm tarihine işaret etmektedir. Mehmet Şefik Efendi hakkında divançesinde yer alan biyografik bilgiler daha sonra Girit'te çıkan İntibah gazetesinde de yer almış ve divançesinde olmayan şiirlerinden örnekler yayımlanmıştır (Baş 2007:105-109). Mehmet Şefik Efendi vaktinin çoğunu Mesnevî okuyarak geçiren Mevlevîliğe intisâb etmiş bir şairdir. Ayrıca onun nüktedân, hoş sohbet ve misafirperver olduğu da ifâde edilmiştir (Sevgi 1992:131-138).

\section{Divançesi}

Mehmet Şefîk Efendi’nin divançesi “Divânçe-i Hanyevî Şefîk Efendi” adıyla H 1293/ M 1877 yılında İstanbul Ahter Matbaasında basılmıştır. Divançenin baş kısmında Hanya Mevlevîhânesi kurucusu Şemsî Dede'ye ait 14 beyitlik Farsça manzum bir takriz yer almaktadır (Kara 2013:30). Matbû divançede 1'i na't olmak üzere 2 kaside, 54 gazel, 1 tahmis, 4 kıt'a, 12 müfred ve 11 tarih vardır. Şiirlerinde "Şefîk" mahlasını kullanmıştır. Divançesinde çoğunlukla Mevlânâ ve Mevlevîlik unsurlarını işlemiştir. Mehmet Şefîk Efendi’nin divançesinden başka bir eseri olup 
olmadığ1 bilinmemektedir. Vâsıf Efendi’nin Mecmu'a-i Medâyih-i Mevlânâ'sında Şefîk Efendi'nin 5 manzumesi vardır. Seçilen şiirlerin hepsi divânçesinde de mevcuttur. ${ }^{1}$ Mehmet Şefîk Efendi İzzet'in muakkibi olduğunu gazellerinde yazmıştır. Bu konuya ayrı bir başlıkla değinilecektir. Nûrî Efendi'den nazire istediğini belirten bir gazeli mevcuttur. Aşk redifli gazelindeki "Oku Vahdet-nâme-i 'Aşkî Şefîk bâ-cân u dil” mısraında Aşkî Efendìye olan hürmetini ortaya koymaktadır (Baş 2014). Nüzhet Efendi bir gazelinin maktaında "Bâğ-1 nazmın gerçi vardır Nüzhetâ bin bülbüli/ Hanya’nın amma Şefîk-i nâdire fermâsı var” demiş, bu ifâde İbnü'1-Emin Mahmud Kemal İnal tarafından "Bâğ-1 nazmın her bülbülü Hanya'nın bülbülü gibi hoş nevâ ise vay o bâğın başına” yazılarak eleştirilmiştir (İnal 1988: c.3). Mehmet Şefik Efendi'nin de Nüzhet Efendi’nin bu gazeline yazdığı bir tahmisi vardır ve "Hâmesidir Nüzhet'in meydân-1 nazm-1 düldüli/ Şimdi mızmâr-1 ma'ârifde gider dizgin tolu" ifâdesiyle Nüzhet Efendi’nin övgüsüne karş1lık vermiştir.

\section{Manzumelerinde Mevlânâ Sevgisi ve Mevlevîlik Unsurları}

Mehmet Şefik Efendi, Hanya Mevlevîhânesinin açılmasına öncülük eden muhiblerden birisidir. Mevlevîhânenin kurucu şeyhi Süleyman Şemsî Dede’nin Şefik Efendi'ye yazdığ1 manzum takrizden yukarıda bahsedilmiştir. Mevlevîhânelerini yöneten Mevlevî şeyhlerinin şiirden anlamaları, yaptıkları görev gereği zorunluluktu. Çünkü, Mevlânâ'nın Mesnevi'sini ve Divân-1 Kebîr'ini okurken ve onların şerhlerini yaparken şiirden anlamak ve belâgâtın inceliklerine vâkıf olmak gerekiyordu (Mermer 2009:13). Böyle bir ortamda yetişen şairin şiirlerinde Mevlânâ sevgisi ve intisâb ettiği tarikatın unsurlarının yer alması bu yüzdendir. Mehmet Şefîk Efendi'nin divânçesinde yer alan ilk gazeli Mevlânâ rediflidir. Aşağıda örneklenen beyitler divançede yer alan gazellerin makta beyitlerinden seçilmiştir. Manzumelerinde görüldüğü üzere Mevlânâ, Şems, Mesnevi, Mevlevîlik sıklıkla yer almıştır:

“Cenāḥ̂-1 'aşk ile pervāz-1 huld-1 vuṣlat olur

Şefik Şems-i ḥaḳikatdir 'aşkẹ-1 Mevlānā” G1/5.

“Müşrif-i dilden küşād et revzen-i 'aşḳı Şefik

Nūr-1 şems-i Mevlevī virsün żiyā her rūz u şeb" G 8/6.

“Ben mürīd-i aşḳııım Monlā-yı Rūmuñ ey Şefik

Feyż-i ‘ālīsi beyān etdi nedir macnā-yı ruȟ" G 15/5.

\footnotetext{
${ }^{1}$ Mecmu'ada yer alan manzumelerden biri Şefîk-i Hanyavî adıyla yer alsa da bu manzume Şefîk Efendi’nin değil Nâbî̀nindir. "Osmanlı Şiirinde Mevlânâ Övgüleri ve Mevlevîlik Unsurları” kitabında, mecmu'adaki bu yanlışlık dipnotla zaten belirtilmiştir.
} 
"Mațla'-yı Şems-i füyūżdur Ḥażret-i Monlā-yı Rūm

Nūr-1 'aşḳ̂ dilde eyler dā’imā envār vār” G 25/6.

"Ya'nī Celālü'd-dīn-i Ḥaḳ bahş̧ende-i envār-1 'aşk

Şems-i münīr-i garb u şarḳ mevle’l-mevālī ḩānımız" G 27/6.

“Mest-i 'aşḳ1 olıcak Hażret-i Mevlānā’nıñ

Buldı ol demde Şefik neş'e-i esrār-1 neşāț" G 33/6.

"Mesnnevī cilm-i ledünnüñ ma`na-yı icmālidir

'Aş̧k-1 Mevlānā ile sen al Şefik andan sebaḳ” G 43/5.

\section{Şefîk'in manzumelerinde görülen Keçeci-zâde İzzet Molla'nın etkisi}

Fuad Köprülü tarafından "klâsik nazmın Tanzimattan önceki son üstâdı" olarak görülen Keçecizâde İzzet Molla derviş ruhlu, olgun ve nüktedan bir şairdir. Mevlânâ Celâleddîn-i Rûmî ve Şems-i Tebrîzîye büyük hayranlık duyan ve ilhâmını geniş ölçüde Mevlevîlikten alan İzzet Molla, gazellerinin çoğunun makta beytinde Mevlânâ’nın adını zikretmiş, onun birçok manzumesini tahmis etmiş ve Şeyh Gâlib’in Hüsn ü Aşk'ına nazîre olarak yazdığı Gülşen-i Aşk mesnevisinde Mevlevîliğin temelindeki aşk felsefesini anlatmaya çalışmıştır (Okçu 2001:561). Aslen Konyalı olan İzzet Molla'nın Mevlevîliği ise "Sā'il-i der-gāh-1 Pĩr'em 'İzzetā ben cedbe-ced/ Müntākildür bāb-1 lutfı vālidüm magfūrdan" beytinden de anlaşıldığı üzere ona ata yadigarıdır. Şair'in Bahār-1 Efkâr'ını Mevlânầya ithâf etmesi bu bağlılı̆̆ın bir göstergesidir (Şahin 2004:35-36). İzzet Molla'nın hem Mevlevîliğe hem Nakşîliğe intisâb ettiği bilinse de bu makalenin konusu ve amacı onun Mevlevîliğe olan bağl1lı̆̆ına dikkat çekmektir.

İzzet Molla'nın etkisi daha çok kendi dönemi şairlerinde ve Tanzimat döneminde bu yolu devam ettiren şairler üzerinde görülür. Onun şiirinden etkilenen ve kendisine nazire yazan şairlerden birisi de Hanyalı Mehmet Şefîk Efendi'dir. ${ }^{2}$ Mehmet Şefik Efendi'nin bir gazelinde “'İzzet gibi 'irfâna Şefîk pey-rev olur mı” dediği şair Keçeci-zâde İzzet Molla’dır. Her iki şairin de Mevlevî oluşu ve manzumelerinde sıklıkla Mevlânâ Celâleddîn-i Rûmîyi anmaları bu etkileşimin sebebinin Mevlevîlikten ötürü olduğunu düşündürtmektedir.

\footnotetext{
${ }^{2}$ İzzet Molla'nın şiirinden etkilenen şairler arasında; Ârif Hikmet, Vâsıf, Osman Nevres, Hızırağa-zâde Said, Sermed, Süleyman Paşa-zâde Fehmî, Zihnî, Senîh, Aynî, Şeref Hanım ve Leylâ Hanım gösterilmiştir. (ŞAHIN: 2004) Biz buna ek olarak Hanyalı Mehmet Şefîk Efendi’yi de ekliyoruz.
} 
Keçeci-zâde İzzet Molla'dan tanzir edilen zemin şiirlerin şairin Bahâr-1 Efkâr Divânı'ndaki gazellerinden seçildiği görülmektedir. Hanyalı Mehmet Şefîk Efendi'nin tanzir ettiği gazeller 5 tanedir. Bu nazirelerin şekil ve muhteva özellikleri açısından karşılaştırılması yapılacaktır.

\section{Vezin Benzerliği}

İki manzume arasındaki nazire ilişkisindeki ilk benzerlik vezin benzerliğidir. Şair zemin şiirle aynı vezinde şiirini yazmıştır. Bu vezinler aruzun "fe ilātün fe ilātün fe ilātün fe ilün", "mef'ūlü fā ilātü mefā' i lü fā'ilün” ve "mef ūlü mefā' i lü mefā' i lü fe ūlün” kalıplarıdır.

\section{Kafiye ve Redif Benzerliği}

İkinci benzerlik ise manzumelerde yer alan kafiye ve rediftir. İlk gazeldeki “-e sabâh" redifi ve “-âr” kafiyesi, ikinci gazeldeki “-i ümîd” redifi ve "-âne” kafiyesi, üçüncü gazeldeki “-i'” kafiyesi, dördüncü gazeldeki “-1 neşât”" redifi ve “-âr” kafiyesi ve son gazeldeki “-îf” kafiyesi her iki şairin manzumelerinde de aynıdır.

\section{Konu, Söyleyiş ve Anlam Benzerliği}

Keçeci-zâde İzzet Molla'nın manzumelerinde işlediği konular Hanyalı Mehmet Şefîk Efendi'de de rastlanmaktadır. Aynı konunun işlendiği bu manzumelerdeki söyleyiş ve anlam benzerlikleri örneklenmeye çalışılacaktır.

Aşağıdaki beytin ikinci mısraında yer alan "zülf-i siyehkâr" ve "infial etmek" kelimeleri ile "zülf”ve "dâra çekmek” arasındaki söyleyiş ve anlam benzerliği dikkat çekicidir:

'İzzetā mihr-i ruh̆-1 yārı nihān itdükce

İnfi' āl itse sezā zülf-i siyeh-kāra ṣabāḥ̣ (İzzet)

Sinne-șāf olmaḳ içün sinnemi șad çāk ederim

Ǵam yimem zülfine ger çekse beni dāre șabāḥ (Şefîk)

Aynı gazelin matla beyitlerine bakacak olursak her ikisi de "bu gice" ile başlamaktadır. Her iki beyitin de "Yâre derdini anlatma ve ondan çare isteme" teması üzerine oluşturulduğu görülmektedir:

$\mathrm{Bu}$ gice ölmez isem yalvarayum yāre șabāh

Bulsun elbette şeb-i ḥicrine bir çāre șabāḥ (İzzet)

Bu gice çekdigimi añladayım yāre șabāh

Şāyed inșāa ider ol derdime bir çāre șabāḥ (Şefîk) 
Sevgilinin iki kaşını mihrâb; yüzünü kıble edinen Şefîk'in beyti ile sevgilinin bakışı ile küfre düşen İzzet' in beyti arasındaki benzerlik göze çarpar:

Hem-pāy-1 nigāhı olalı küfr ile ĩmān

'Ālemde ne büt-ḩāne ḳodı çeşmi ne cāmi' (İzzet)

İmān-1 ḥaḳikatle dü ebrūsını miḥ̂āb

'Uş̧̧āḳ̂-1 cemāliñ edinüp ḳıble vü cāmi' (Şefîk)

Her iki şair de istek bahçesinde sevincin dikensiz gülünün bulunmadığını yani âşı̆̆ın isteğine ulaşamama durumunu ifâde etmiştir:

Var mı başdan başa baḳ bir gül-i bĩi-hāār-1 neşāṭ
İdesin tā kim anı ziviver-i destār-1 nȩ̧āṭ (İzzet)
Eylemez gāle-i āmālde biri kār-1 neşāạt
Bāàg-1 mațlabda bulunmaz gül-i bì-ḩār-1 neşāṭ (Şefîk)

Sevgilinin dudağının üstündeki beninin güzelliği karşısında bütün sözlerin tükendiğini belirten İzzet'in beyti ile sevgilinin dudağınının güzelliğini betimlemeye şairlerin söyleyecek söz bulamadığını belirten Şefîk’in beyti neredeyse aynıdır:

Noḳța-i hāal-i lebinde tükenür cümle sühan

İdemem ḥüsnini yāruñ saña bir bir ta rị (İzzet)

Nükte-dān söz bulamaz vaṣf-1 leb-i ḥüsniñde

Șun '-1 Ḥaḳ aḥsen-i taḳvimdir olunmaz tavșif (Şefîk)

Nazire Yazılan Şairin Adının Yazılması

Hanyalı Mehmet Şefîk Efendi dört gazelinde İzzet'e pey-rev olduğunu belirtir. Üç gazelinin ise zemin şiiri mevcuttur. Bu beyitler şu şekildedir:

'İzzet gibi ‘irfāna Şefilk pey-rev olur mı

Raḥmı var iken bülbül-i gülzār-1 hakịkatat (G 3/5)

“Tāb-1 'aşḳıyla Şefik pey-rev olup 'İzzet'e yaz

Oḳusun bu gazeli 'arż ide Hünkār'a șabāḥ̣” (G 14/6) 
"Naẓm-1 cenāb-1 '̇̇zzete pey-rev olur iseñ

Ābād olur Şefik dil-i virāne-i ümid”” (G 16/4)

"Tanzirine haddiñ mi seniñ hāmeñe 'İzzet

Evc-i hünere žātı olup mihre mețāli’” (G 35/5)

\section{Sonuç}

19. yüzyıl Mevlevî şairlerinden Hanyalı Mehmet Şefîk Efendi'nin manzumelerinde nazire yazdığını belirttiğgi İzzet’in yine kendisi gibi Mevlevîliğe intisâb etmiş ve manzumelerinde sıklıkla Mevlânâya bağllliğını ifâde etmiş şair Keçeci-zâde İzzet Molla olduğu tespit edilmiştir. Şairin divânları incelenmiş ve Bahâr-1 Efkâr divanında yer alan gazellerin tanzir edildiği ortaya çıkmıştır. Hanyalı Mehmet Şefîk Efendi’nin şiirlerinin edebi değer açısından kuvvetsiz sayılması bazı şiirlerinin nazire olup olmadığıyla ilgili şüphe uyandırmıştır. Fakat Şefîk'in birçok şiirinde Keçeci-zâde İzzet Molla'dan etkilendiği açıktır. Nazireler, şekil ve muhtevâ yönünden zemin şiirlerle karşılaştırılmış ve vezin, kafiye ve redif ortaklığı olan 5 manzumede konu, söyleyiş ve anlam benzerliklerine rastlanmıştır. Ayrıca her iki şair de şiirlerinde Mevlânâ ve Mevlevîlik unsurlarına yer vermiştir. Diğger şiirlerindeki benzerliklerden biri de budur.

Osmanlı toplum hayatında görülen usta-çırak ilişkisi şiirde de kendisini göstermiş ve bazı nazireler "üstad şairleri izlemek" maksadıyla yazılmıştır. Hanyalı Mehmet Şefík Efendi’nin Keçeci-zâde İzzet Molla'nın şiirlerini tanzir edişinin nedeni ona duyduğu saygı, ilgi ve hayranlık dolayısıyla olduğu düşünülmektedir. Nazirelerinde iddiasız ve saygilı bir üslup hâkimdir.

Hanyalı Mehmet Şefîk Efendi taradığımız kaynaklarda "edebî değeri düşük" şiirler yazan bir şair olarak yer alsa da Mevlevî derviş Vâsıf Efendi'nin 19. yüzyllın sonunda tertip ettiği "Mecmû̉a-i Medâyîh-i Mevlânâ" mecmuasında Şefîk Efendi'nin 5 manzumesine yer vermesi onun Mevlevî muhitinde bilindiğini göstermektedir. Divançesi incelendiğinde muakkibi olduğunu belirttiği şair İzzet'e yazdığı nazireler belirlenmiş ve İzzet’in de Keçeci-zâde İzzet Molla olduğu divânları incelenerek tespit edilmiştir. 


\section{EK 1}

Keçeci-zâde İzzet Mollâ:

fe 'ilātün fe ilātün fe ilātün fe ilün

Bu gice ölmez isem yalvarayum yāre șabāh

Bulsun elbette şeb-i hiicrine bir çāre șabāḥ

Kanaram cām-1 mey-i vașluna mirüm bu gice

Beni öldürdecek olsañ dahi hünkāra șabāh

Şām-1 fürḳatden ușandum ne olursa olsun

Varup ibrām ideyüm vaṣlını dil-dāra șabāḥ

Fāş olursa bu gice çekdigim āzār u sitem

Ne disem ben ne yalan söylesem ag̀yāra șabāḥ

Mihr-i ruhsārını gösterdi ser-i zülfinden

Reşk ile itdi giriābānın iki pāre șabāḥ

'̇̇zzetā mihr-i ruḩ-1 yārı nihān itdükce

İnfi 'āl itse sezā zülf-i siyeh-kāra șabāḥ

Böyle rūşen mi olur Şems-i hüdādan dolayı

Müntesib olmasa ger Ḥazret-i Hünkāra șabāḥ (İzzet

G 65)

Hanyalı Mehmet Şefik Efendi:

fe ilātün fe ilātün fe ilātün fe ilün

Bu gice çekdigimi añladayım yāre șabāḥ

Şāyed inșāf ider ol derdime bir çāre ṣabāḥ

Bu şeb āgūşş-1 maḥabbetde alup yārimi ben

Kạldı yüz karalı̆̆ı nekbet-i ag̀yāre șabāḥ

Şeb-i hicrānda yanup āteş-i āhımla cihān

Ḩaberi olmadı șordum diyü dil-dāre șabāḥ

Etdigüñ cevre mükāfāt bu gice zevḳ idelim

Varsin ag̉yārıñ ola sinnesi biñ pāre șabāḥ

Sine-șāa olmaḳ içün sinnemi șad çāk ederim

Ġam yimem zülfine ger çekse beni dāre șabāḥ
Tāb-1 'aşkıyla Şefiḳ pey-rev olup 'İzzet'e yaz

Oḳusun bu gazeli 'arż ide Huünkār'a ṣabāḥ (Şefîk G

14)

\section{EK 2}

Keçeci-zâde İzzet Mollâ:

mef ūlü fā ìlātü mefāe i lü fã ìiün

Yā Rab y1ḳ̂lsa bāri şu mey-ḩāne-i ümiñd

Ṭolsa şarāb-1 ye's ile peymāne-i ümĩ d

Bah̆t-1 siyāh perde-keş oldı merāmına

Şem '-i husụuli görmedi pervāne-i ümìd

Dest-i ḳader ki 'uḳde vire zülf-i mațlaba

Bi-hūdedür müdāfa 'a-i şāne-i ümĩd

Rāḥat yüzin görür mi cihānda ser-i țaleb

Ye's olmasa visāde-i kāşāne-i ümĩd

Maḥṣūl-i ye'se żay'a-i 'ömrin tebāh ide

Bu mezra'-1 fenāya eken dāne-i ümĩd

'İzzet ḳalur iseñ daḩi esvāḳ-1 ye'sde

İtme saḳın müsāferet-i ḩāne-i ümĩd

Ey mürğ-i dil ne çıḳdı bu āvāre gezmeden Der-gāh-1 Pirre düş ki odur lāne-i ümìd

(İzzet G 84)

\section{Hanyalı Mehmet Şefik Efendi:}

mef ūlü fā ilātü mefāe i lü fā ilün

Mest itdi girmeden dili meyhāne-i ümĩd

Boş șundı soñra destime peymāne-i ümĩd

Pek çoḳ dolaşdı yanmag̉a şem '-i vișāliñe

Yol bulmadı merāmına pervāne-i ümind

Fahr eylemez kemāl u ma ārifle ehl-i dil

Zinet bulur $m 1$ țabl ile kaşāne-i ümird

Naẓm-1 cenāb-1 'İzzete pey-rev olur iseñ

Ābād olur Şefiḳ dil-i virāne-i ümìd 
Ye'se gelir mi sāye-i Moñlada bendesi

Pertev-feşān-1 'aşḳ olıcak hāane-i ümìd (Şefîk G 16)

\section{EK 3}

Keçeci-zâde İzzet Mollâ:

mef' ūlü mefā' $\underset{\sim}{\mathbf{i}}$ lü mefā' $\underset{\sim}{\mathbf{i}}$ lü fe 'ūlün

Olsaḳ 'acabā kimse olur mı bize māni

Fıstıḳlı'da bir dịde-i badām ile ḳāni

Hem-pāy-1 nigāhı olalı küfr ile ĩmān 'Ālemde ne büt-ḩāne ḳodı çeşmi ne cāmi

Sūret bulamaz āyet-i vaḥdetde vücūhāt Ol yüzde degül İbni Keŝirirüñ sözü nāfi

A ġırca gelür cevher-i deryā-yı ene'l-Ḥaḳ İtmezse taḥammül n'ola eṣdāf-1 mesāmi

Ser-pençe-i hur-şid-i hüner oldı bu beş beyt 'İzzet ne revā burc-1 Keşān'da ola tāli

Üftādesidür zerre gibi hażzet-i Şems'üñ

Bir dilde ki envār-1 ḥaḳiḳat ola lāmi

( İzet G 251)

\section{Hanyalı Mehmet Şefik Efendi:} mef' ūlü mefā' i lü mefā' i lü fe 'ūlün

Ey sāḳi -i 'aşḳ bezmiñe ger olmasa mānic La '1-i lebiñ emsem olurum Kevŝer'e kāāni

İmān-1 ḥaḳiḳatle dü ebrūsını miḥrāb 'Uşşāḳ-1 cemāliñ edinüp ḳıble vü cāmi'

Sāhil-res-i vaḥdet olan erbāb-1 ḥaḳāyıḳ Vā'iẓ olamaz keŝret-i ḳāliñ aña nāfi

Cūş eyler o ḳațre ki düşer vaḥdet-i baḥre

Olmaz mı Ene'1-Haḳ o vaḳt-i zịb-i mesāmi

Tanẓirine ḥaddiñ mi seniñ ḩāmeñe 'İzzet Evc-i hünere zāâtı olup mihre mețāli
'Aşḳıında Şefik ẓerre iken Hażret-i Şemsiñ

Envār-1 tecellisisi yine sinede lāmi

(Şefîk G 35)

\section{EK 4}

Keçeci-zâde İzzet Mollâ:

fe ilātün fe ilātün fe ilātün fe ilün

Var mı başdan başa baḳ bir gül-i bĩi-ḩār-1 neşāṭ

İdesin tā kim anı ziver-i destār-1 neşāṭ

Az içer rıṭl-1 girānı gamını bu bezmüñ

Kāni' -i cür'a olan rind-i sebük-bār-1 neşāț

İtme bu mey-kedenüñ derd-i gamından şekvā

Çekmek isterseñ eger sāğar-1 ser-şār-1 neşāṭ

Şevk-i sāgaardan alur pertevi ḳașr-1 neş’e

Cāmdan rūşen olur revzene-i dār-1 neşāṭ

Dil-i ma mūr ḩarābāta yaraşmaz 'İzzet

Yapmasun hāạtır-1 vĩrānemi mi 'mār-1 neşāṭ

Bulamazsın bu fenā bāğda sebz-āb-1 șafā

Der-geh-i Pirr'dedür ne'şe-i esrār-1 neşāṭ

(İzzet G 245)

\section{Hanyalı Mehmet Şefik Efendi:}

fe ilātün fe ilātün fe ilātün fe ilün

Eylemez gāle-i āmālde biri kār-1 neşāṭ

Bā $\dot{g}-1$ maṭlabda bulunmaz gül-i bì-ḩār-1 neşāt

'Ārif-i rāh-1 ḥ̣aḳiḳat gamı fitrāke aṣar

Kūy-1 ma nāya erer merd-i sebük-bār-1 neşāṭ

Rind-i mey hem-dem eder pĩr-i mugānı yalñız

Bezm-i vaḥdetde bulur zevḳ̣le âŝār-1 neşāṭ

Revnāḳ-efzā-yı șafā sāḳi elinden sāgar

Ṭolaşınca eder ehl-i dile iŝār-1 neşāṭ 
'Aḳd edüp pirr-i muḡān duht-1 rezi 'āşı̣ıına Anı hị boş mu ḳoyar g̉ayr o kām-kār-1 neşāt

Mest-i 'aşḳı olıcaḳ Hażret-i Mevlānā'nı̃̃ Buldı ol demde Şefilk neş'e-i esrār-1 neşāt (Şefîk G 33)

\section{EK 5}

\section{Keçeci-zâde İzzet Mollâ:}

fe ilātün fe ilātün fe ilātün fe ilün

Var mı șahbā gibi hem-bezm idecek rind-i ẓarif Görmedük varsa 'araḳdan daḩı bir rūḥ̂ $\mathbf{~ h ̧ a f i f f ~}$

\section{Noḳta-i ḩāl-i lebinde tükenür cümle süh̆an} İdemem hü̈snini yāruñ saña bir bir ta 'rif

Şekker-āb olmış idi la 1-i lebüñle dehenüm Ḳ1ldı efsūn-1 hațuñ beyne-hümāyı te' liff

Naẓmda ḳafiyenüñ ḥüsnine diḳkat lāzım

Miṣra -1 ḳāmetüñe itme rakịibi terdịf

O zamāndan beri būs-1 lebüni 'ahd itdüm

Çoḳ ŝenā eyledi sulțānumı bir zạât-1 şerif

Nokțāāi hāli mu 'ammā-yı dehānında gören Șanki buldum mı șanur bilse de gūyā tașḥif

Añdırur gonçeyi ammā ki şarābìye baḳar İdebüldüm mi 'aceb la lüñi sāḳi ta rị̂

Hูaț-1 sebz içre gören dir o siyeh hāal-i ruhı Ḥarem-i Kābe’ye cem ‘ eyledi sādātı şerif
Ra 'şe geldi eline 'İzzet ag̉ardı saḳaluñ

Bārì sev köhnesini tāze seversin a ḥeriff

Kendi âsāārını furșat bulamaz taḥirire

Vāṣıfuñ itmeden eş ārını ḩāmem tavșif

Maẓhar-1 luṭfi ola Şems-i felek-der-gāhuñ Ḥażret-i Pịir'e emānet o süḩan-dān-1 lațif (İzzet G 267)

\section{Hanyalı Mehmet Şefik Efendi:} fe ilātün fe ilātün fe ilātün fe ilün

Duht-1 rez bezme gelince bayilur rind-i zarif Meyli yoḳ olsa 'araḳ bir de sebük-rūhn-1 hafí

Nükte-dān söz bulamaz vaṣf-1 leb-i ḥüsniñde Sun '-1 Ḥak aḥsen-i taḳvimdir olunmaz tavșif

Nüzhet-i gülşeni terk etdi bütün 'andelibe Kūşe-i mey-kededir rind-i gülistān-1 lațịf

Kurtarır keŝret ile dag̉dag̀a-i 'ālemden Cām-1 ser-şārı eger sāḳi ederse taż î if

Rind-i 'aşk șundı bize bezm-i ezelde bir cām 'Aş়̧̣ ile beynimizi etdi ile' 1 -ān te' lif

Ḥüsn-i yār oldug̉u veş āyine-i dilde nümā Şive-i hüsnü ne mümkin ḳalem etsün ta rịf

Sırr-1 'aşḳ̂ işidince gūşş-1 cān ile Şefik Dil șımāḩında o demden berü etdi teşnif (Şefîk G 40) 


\section{Kaynakça}

Arslan, Mustafa (2012). “Şeyh Gâlib ile Keçeci-zâde İzzet Molla'nın Gazelleri Arasında Nazire İlişkisi.” Turkish Studies. Volume 7/1 Winter 2012, p. 251-282, Turkey.

Baş, Mehmet Şamil (2007). Aşkî Mustafa Efendi’nin Vahdet-nâme Mesnevisi (Metin, Muhteva, Tahlil). İzmir: Dokuz Eylül Üniversitesi Sosyal Bilimler Enstitüsü Yayımlanmamış Yüksek Lisans Tezi. s.105-109.

Ceylan, Ömür-Y1lmaz, Ozan (2005). Hazâna Sürgün Bahâr. Keçecizâde İzzet Molla ve Dîvân-1 Bahâr-1 Efkâr.İstanbul. Kitap Sarayı.

İnal, İbnü'l-Emin Mahmud Kemal (1988). Son Asır Türk Şairleri. C.3. İstanbul: Dergâh Yay. İsen, Mustafa (2005). "Türler”. Eski Türk Edebiyatı El Kitabı. Ankara: Grafiker Yay. s.262.

İzzet Molla, Keçeci-zâde Mehmed İzzet

Efendihttp://www.turkedebiyatiisimlersozlugu.com/index.php?sayfa=detay\&detay=6375 [erişim tarihi: 21.03 .2018 ]

Kara, İsmail (2013). Hanya/Girit Mevlevîhânesi Şeyh Ailesi-Müştemilâtı-Vakfiyesi-Mübadelesi. İstanbul: Dergâh Yay. s.30.

K1lıç, Filiz (2004). "Giritli Divan Şairleri” Hacı Bektaş Veli Araştırma Dergisi, S. 32. Ankara. s.275-294.

Köksal, M. Fatih (2006). Sana Benzer Güzel Olmaz, Divan Şiirinde Nazire, Ankara: Akçă̆ Yay. s. 101.

Kurnaz, Cemal (2007). Osmanlı Şair Okulu, Ankara: Birleşik Yayınevi. s. 41.

Macit, Muhsin (1996). Divân Şiirinde Âhenk Unsurları, Ankara:Akçă̆ Yayınları.

Mehmed Şefik Efendi,

Hanyalıhttp://www.turkedebiyatiisimlersozlugu.com/index.php?sayfa=detay\&detay $=6044$ [erişim tarihi: 21.03.2018]

Mehmet Şefik Efendi (1876). Divançe-i Hanyevî Şefîk Efendi. İstanbul: Ahter Matbaası.

Mermer, Ahmet, Hidayetoğlu S., Erdoğan M., Koç Keskin N. (2009). Osmanlı Şiirinde Mevlânâ Övgüleri ve Mevlevilik Unsurları. Türkiye Diyanet Vakfı Yay.

Nurî Osman Hanyevî (2006). Girit Şâirleri (Tezkire-i Şu’arâ-yı Cezire-i Girid). (hzl. Orhan Kurtoğlu). Ankara: Akçă̆ Yay.

Sevgi, Ahmet (1993). "XIX. Yüzyıl Mevlevî Şairlerinden Mehmet Şefîk Efendi ve Dîvânçesi”, VI. Millî Mevlânâ Kongresi. (24-25 Mayıs 1992). Konya s.131-138.

Şahin, Ebubekir Sıddık (2004). Keçeci-zâde İzzet Molla’nın Divanları: Bahâr-1 Efkâr ve Hazân-1 Âsâr. Ankara: Ankara Üniversitesi Sosyal Bilimler Enstitüsü Doktora Tezi. s.35-36.

Okçu, Naci (2001). TDV İslam Ansiklopedisi, C.23 S. 561.

Tolasa, Harun (1983). Sehî, Latîfî, A̧şık Çelebi Tezkirelerine Göre 16. Yy.da Edebiyat Araştırma ve Eleştirisi, İzmir: Ege Üniversitesi Edebiyat Fakültesi.

Yavuz, Kemal (2013). “Türk Şiirinde Nazire”, İstanbul: Divan Edebiyatı Araştırmaları Dergisi. 